\title{
Large gastrointestinal stromal tumor size does not imply early recurrence
}

This article was published in the following Dove Press journal:

International Medical Case Reports Journal

25 February 2010

Number of times this article has been viewed

\section{Mohamed Abdel-Ghaffar \\ Consultant of Surgery, Sadat General Hospital, First zone, Madinet Al Sadat, Menoufia, Egypt}

\begin{abstract}
A 28-year-old female presented with a huge intra-abdominal mass. Initially a mesenteric mass was diagnosed, but her tumor was found to be a gastrointestinal stromal tumor (GIST). Laparotomy was performed. The mass was resected en bloc with clear surgical margins in January 2007. It was found to be $20 \times 18 \times 16 \mathrm{~cm}$. In order to remove the tumor, the left half of transverse colon with its mesocolon, spleen, body and tail of pancreas, and a part of the small intestine had to be removed. The mass was tightly attached to these viscera. The tumor was surgically removed three years ago. The pathology report of the case presented places the tumor in the high-risk category. The tumor had a relatively high mitotic index. It was positive for CD117 and CD34 stains and also positive for smooth muscle actin. Although the patient did not receive adjuvant chemotherapy, no signs of local recurrence or distant metastasis could be recognized on follow up. Surgery remains the standard initial management for all localized GISTs. The tumor should be removed en bloc, with clear surgical margin. The case presented indicates no association of tumor size with early local recurrence of the tumor or early distant metastasis.
\end{abstract}

Keywords: GIST, gastrointestinal stromal tumor, metastasis

\section{Introduction}

Gastrointestinal stromal tumors (GISTs) are rare in the Egyptian population. GISTs are the most common nonepithelial tumors of the gastrointestinal tract. ${ }^{1}$ Surgery is the primary therapy of choice and for a long time has been the only effective therapy for GIST with an overall five-years survival rate of $45 \%-55 \%{ }^{2}$ Uncertainty remains whether an individual tumor is benign or has the potential for metastatic spread. ${ }^{3}$

\section{Case presentation}

A 28-year-old Egyptian female presented with abdominal pain and distension. Written informed consent was obtained from the patient for publication of this case report and accompanying images. There was no family history of malignant tumors. Clinical examination revealed a large abdominal mass in the upper left quadrant of the abdomen. An abdominal computerized tomography (CT) imaging demonstrated an intra-abdominal mass related to the upper border of pancreas and mesentery of transverse mesocolon, without invasion of adjacent viscera. CT examination did not detect any abdominal distant metastasis. Provisional diagnosis was a huge mesenteric mass. Laparotomy was performed. The mass was resected en bloc with clear surgical margins in January 2007. It was found to be $20 \times 18 \times 16 \mathrm{~cm}$. In order to remove the tumor, the left half of transverse colon with its mesocolon, spleen, body and tail of pancreas, and a part of the small intestine had to be removed (Figures 1 and 2).
Correspondence: Mohamed Abdel-Ghaffar 19, Sixth zone, Madinet Al Sadat, Menoufia, Egypt, zip: 32897

Tel +2010 III 5842

$\mathrm{Fax}+20482600826$

Email mohaghaffar@yahoo.com 


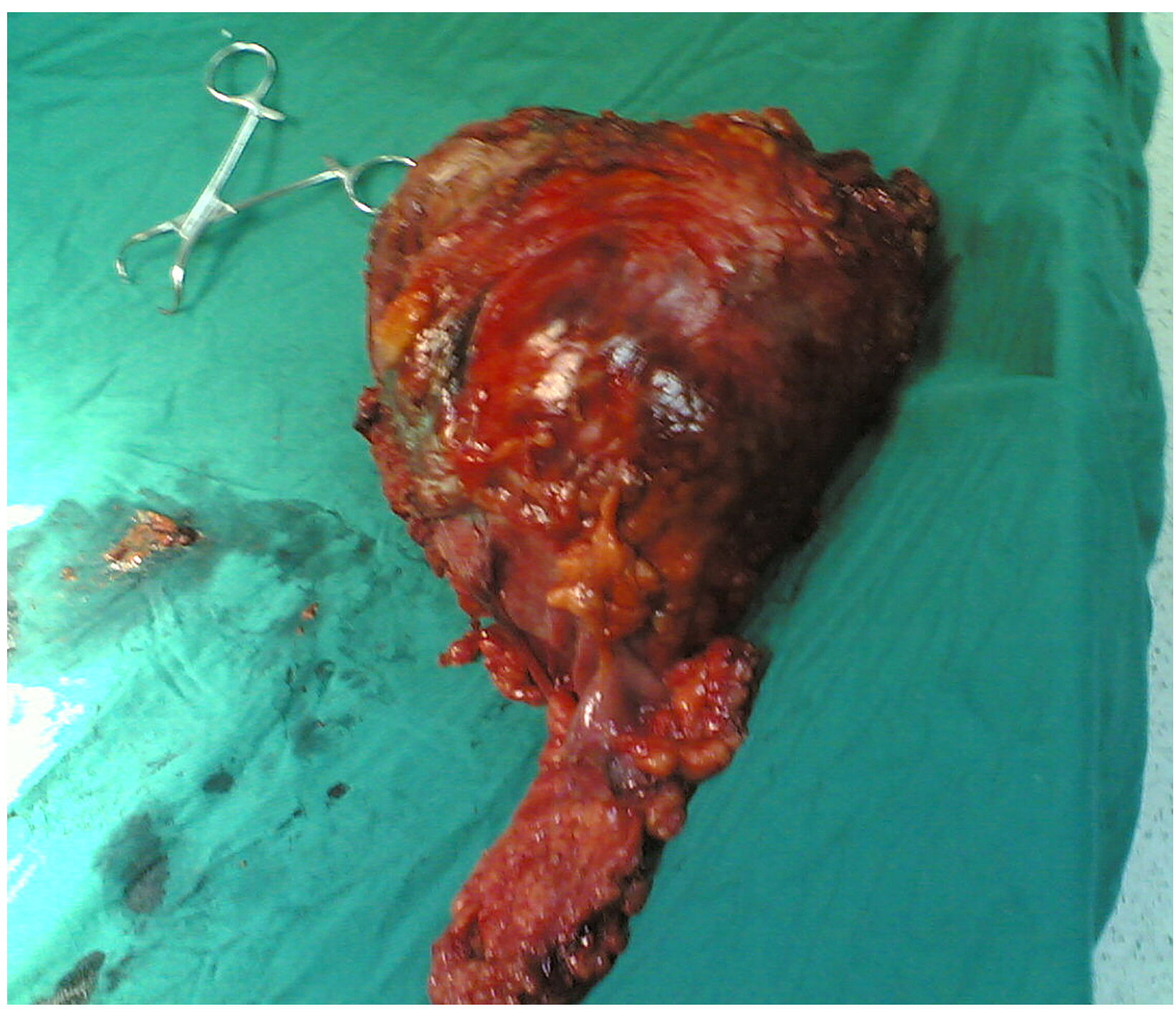

Figure I The anterior aspect of a GIST presenting as a huge abdominal mass attached to the left half of transverse colon with its mesocolon, body and tail of pancreas, and a part of the small intestine removed from a 28 -year-old female.

Abbreviation: GIST, gastrointestinal stromal tumor.

The mass was tightly attached to these viscera. The spleen was also removed because the splenic vein was ligated as it was traversing the tumor mass.

Pathology results demonstrated a malignant noncapsulated gastrointestinal stromal tumor. Tumor showed an advancing pushing border. The tumor was attached to the removed adjacent viscera without invasion. The tumor proved to be GIST. Histopathology examination revealed that local excision was complete with clear margins. The tumor consisted of spindleshaped cells with twisted nuclei. There was a marked myxoid change. Numerous mast cells were demonstrated. Mature fat cells were demonstrated in clusters within the tumor tissue (Figure 3). The tumor cells were positive for CD117 and CD34 stains and were also focally positive for smooth muscle actin. They were found to be negative for desmin and S100 protein immunochemical stains. The tumor had 7 mitoses per 50 high-power fields (HPFs).

The postoperative period passed smoothly except for a mild wound infection. No chemotherapy was given to the patient. The patient was followed-up for three years with an abdominal CT examination every six months and no signs of local recurrence was found. Investigations also revealed no distant metastasis.

Follow-up of the case for the next five years is planned to detect tumor recurrence or distant metastasis.

\section{Discussion}

Gastrointestinal stromal tumors (GISTs), although relatively rare, comprising only $0.1 \%$ to $3 \%$ of all gastrointestinal neoplasms, are the most common mesenchymal tumors of 


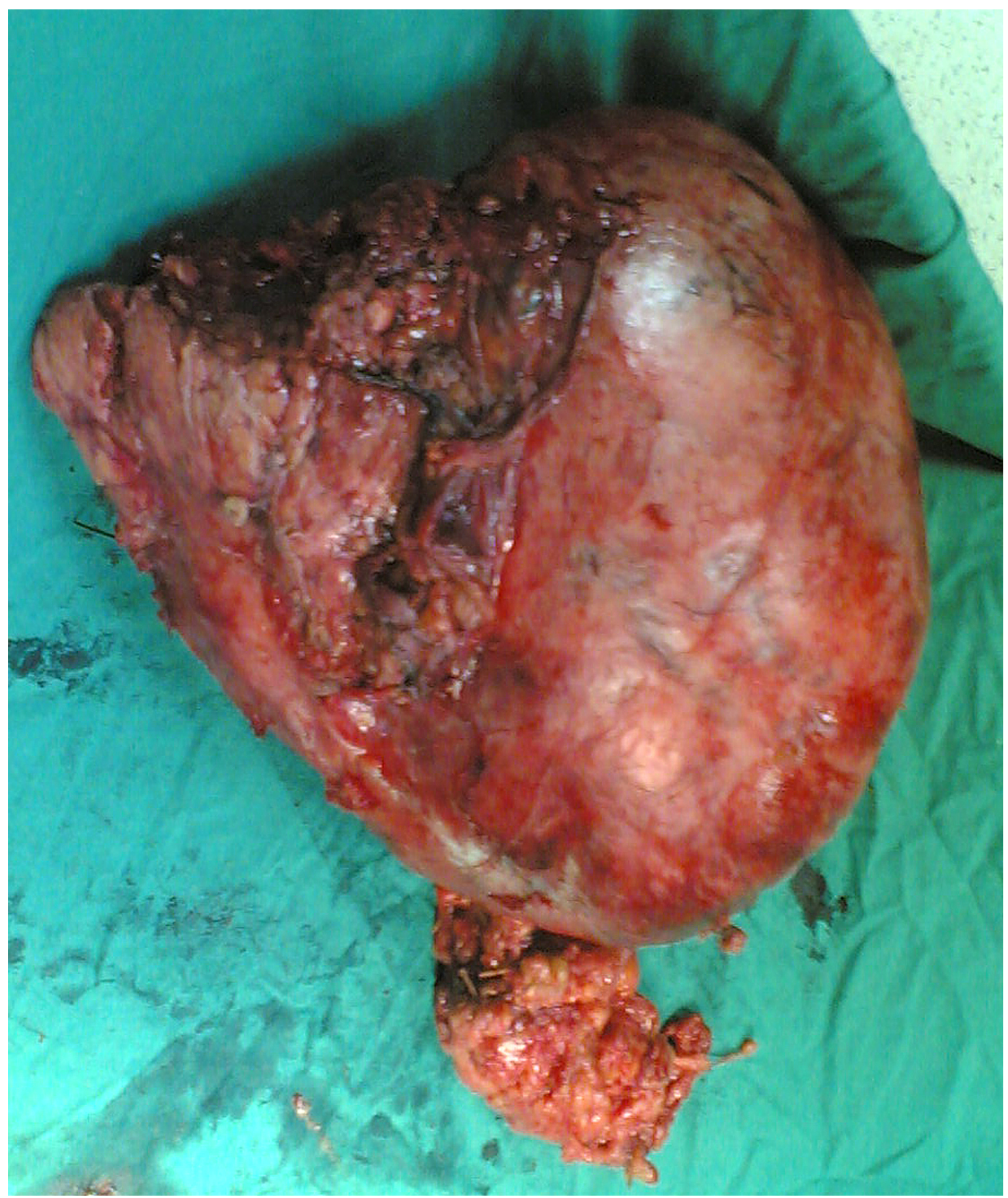

Figure 2 The posterior aspect of a GIST presenting as a huge abdominal mass attached to the left half of transverse colon with its mesocolon, body and tail of pancreas, and a part of the small intestine removed from a 28-year-old female.

Abbreviation: GIST, gastrointestinal stromal tumor. 


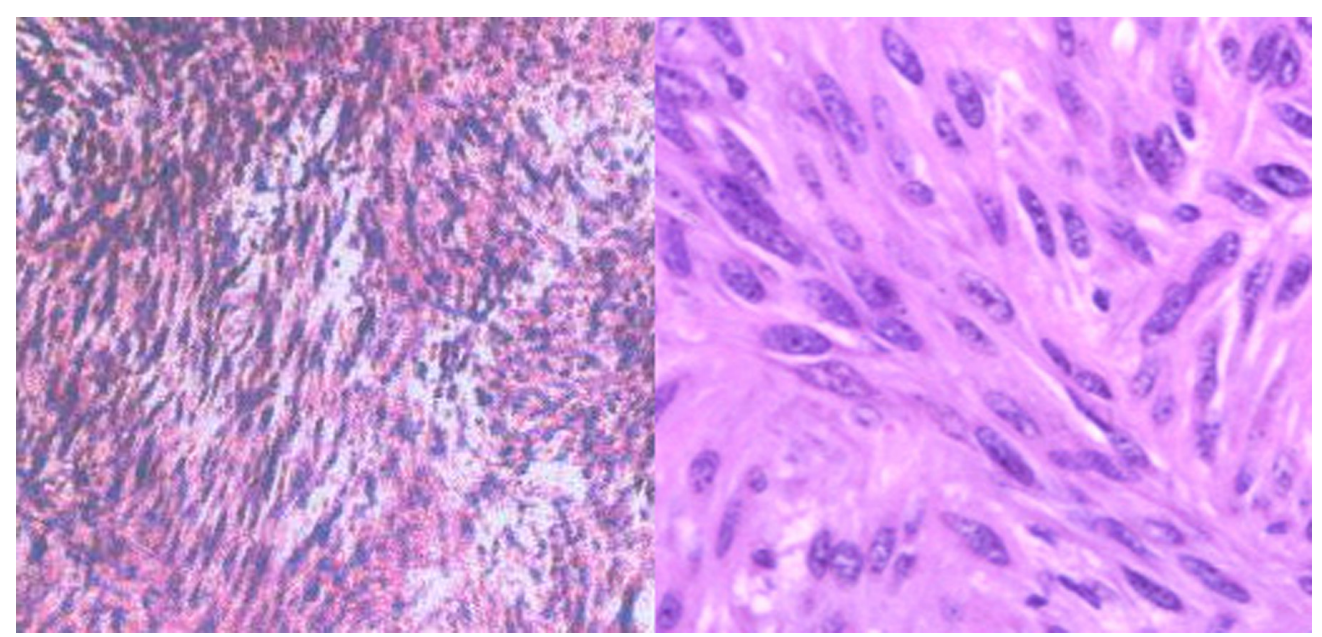

Figure 3 The pathological examination of a GIST presenting as a huge abdominal mass removed from a 28 -year-old female. Abbreviation: GIST, gastrointestinal stromal tumor.

the gastrointestinal tract. ${ }^{4}$ The vast majority of patients with GIST did not inherit mutations that cause GIST from their parents. Instead the initiating mutation developed in one or more cells sometime during their life. Acquired mutations in the KIT proto-oncogene have been found to be involved in the pathogenesis of GISTs, ${ }^{5}$ and germline KIT mutations have been identified in rare cases with multiple occurrences of GIST among blood relatives. ${ }^{6}$ This mutation starts a chain of events that eventually develops into GIST. Despite recent advances in chemotherapeutic regimens, such as introduction of targeted therapy with inhibitors of tyrosine kinase receptors, ${ }^{7}$ surgical resection is still considered the treatment of choice for GIST. ${ }^{8}$ The efficacy of chemotherapy is low, with response rates less than $10 \% .{ }^{9}$ GIST does not involve the bowel wall concentrically. As a result bowel obstruction is rare, despite the large size of the GIST. ${ }^{10}$ Despite apparently complete resection with clear margins, the recurrence rate is high; hepatic or mesenteric recurrence occurs in $40 \%-90 \%$ of patients undergoing apparently curative surgery. ${ }^{11}$ This may be partly due to tumor rupture leading to mesenteric implants; hence, the risk of recurrence emphasizes the importance of meticulous surgery. ${ }^{12}$ For this reason, percutaneous biopsy is best avoided. ${ }^{13}$ Eighty percent of GISTs recurrences occur within two years of excision. ${ }^{14}$ Tumor size, mitotic index, and site of the tumor are three key prognostic features used to assess risk of GIST recurrence. DeMatteo and colleagues reported that tumor size greater than $10 \mathrm{~cm}$ was a significant risk factor for recurrence. ${ }^{15}$ Machado-Aranda and colleagues described the prevalence and characteristics of patients with confirmed GIST in a community hospital over a six-year period. In surgically resected tumors, a $42 \%$ recurrence rate was found with a median average time of recurrence of 22 months. Pathologic grading and type of surgery were not predictors of rate and timing of recurrence. ${ }^{16}$ The pathology report of the case presented places the tumor in the highrisk category. The tumor had a relatively high mitotic index. It was positive for CD117 and CD34 stains and also positive for smooth muscle actin. Neither early recurrence nor distant metastasis was identified after three years of follow up. The case presented indicates no association of tumor size with early local recurrence of the tumor or early distant metastasis. The combination of large tumor size, high mitotic index and KIT-positivity was not also associated with early tumor recurrence. It is obvious that this does not exclude future recurrence or metastasis. The patient case should be monitored thoroughly in the next seven years to identify any signs of local or distant recurrence.

\section{Conclusion}

GIST is a new classification for a group of mesenchymal tumors. These tumors are different in presentation and behavior. Surgery remains the standard initial management for all localized GISTs. The tumor should be removed en bloc, with clear surgical margin. The case presented indicates no association of tumor size with early metastasis of the tumor.

\section{Disclosures}

The authors report no conflicts of interest in this work.

\section{References}

1. Miettinen M, Lasota J. Gastrointestinal stromal tumors - definition, clinical, histological, immunohistochemical, and molecular genetic features and differential diagnosis. Virchows Arch. 2001;438(1):1-12. 
2. DeMatteo RP, Lewis JJ, Leung D, et al. Two hundred gastrointestinal stromal tumors: recurrence patterns and prognostic factors for survival. Ann Surg. 2000;231(1):51-58.

3. Fletcher CDM, Berman JJ, Corless CL, et al. Diagnosis of gastrointestinal stromal tumors: a consensus approach. Hum Pathol. 2002;33(5): 459-465.

4. Sakurai S, Fukasawa T, Chong JM, et al. C-kit gene abnormalities in gastrointestinal stromal tumors (tumors of interstitial cells of Cajal). Jpn J Cancer Res. 1999;90(12):1321-1328.

5. Rubin BP, Singer S, Tsao C, et al. KIT activation is a ubiquitous feature of gastrointestinal stromal tumors. Cancer Res. 2001;61(11):8118-8121.

6. Maeyama H, Hidaka E, Ota H, et al. Familial gastrointestinal stromal tumor with hyperpigmentation: Association with a germline mutation of the c-kit gene. Gastroenterology. 2001;120(1):210-215.

7. Shawer LK, Slamon D, Ullrich A. Smart drugs: tyrosine kinase inhibitors in cancer therapy. Cancer Cell. 2002;1(3):117-123.

8. Pierie JP, Choudry U, Muzikansky A, Yeap BY, Souba WW, Ott MJ The effect of surgery and grade on outcome of gastrointestinal stromal tumors. Arch Surg. 2001;136(4):383-389.

9. Dematteo RP, Heinrich MC, El-Rifai WM, Demetri G. Clinical management of Gastrointestinal stromal tumors: before and after STI-571. Hum Pathol. 2002;33(5):466-477.
10. Sandrasegaran K, Rajesh A, Rydberg J, Rushing DA, Akisik FM, Henley JD. Gastrointestinal stromal tumors: Clinical, radiologic, and pathologic features. AJR Am J Roentgenol. 2005;184(3):803-811.

11. Dematteo RP, Lewis JJ, Leung D, Mudan SS, Woodruff JM, Brennan MF. Two hundred Gastrointestinal stromal tumors: recurrence patterns and prognostic factors for survival. Ann Surg. 2000;231(1):51-58.

12. Dematteo RP. The GIST of targeted cancer therapy: a tumor (gastrointestinal stromal tumor), a mutated gene (c-kit), and a molecular inhibitor (STI571). Ann Surg Oncol. 2002;9(9):831-839.

13. Pidorecky I, Cheney RT, Kraybill WG, Gibbs JF. Gastrointestinal stromal tumors: current diagnosis, biologic behavior, and management. Ann Surg Oncol. 2000;7(9):705-712.

14. Samiian L, Weaver M, Velanovich V. Evaluation of gastrointestinal stromal tumors for recurrence rates and patterns of long-term follow-up. Am Surg. 2004;70(3):187-191; discussion 191-192.

15. DeMatteo RP, Gold JS, Saran L, et al. Tumor mitotic rate, size, and location independently predict recurrence after resection of primary gastrointestinal stromal tumor (GIST). Cancer. 2008;112(3): 608-615.

16. Machado-Aranda D, Malamet M, Chang YJ, et al. Prevalence and management of gastrointestinal stromal tumors. Am Surg. 2009;75(1) $55-60$.
International Medical Case Reports Journal

\section{Publish your work in this journal}

The International Medical Case Reports Journal is an international, peer-reviewed open-access journal publishing original case reports from all medical specialties. Previously unpublished medical posters are also accepted relating to any area of clinical or preclinical science. Submissions should not normally exceed 2,000 words or

\section{Dovepress}

4 published pages including figures, diagrams and references. The manuscript management system is completely online and includes a very quick and fair peer-review system, which is all easy to use. Visit http://www.dovepress.com/testimonials.php to read real quotes from published authors.

Submit your manuscript here: http://www.dovepress.com/international-medical-case-reports-journal-journal 